Letter to the Editors

\title{
Clinical predictors of refuse from percutaneous coronary intervention in patients with acute myocardial infarction: which factors are really matters?
}

\author{
Yulia V. Popova, Alexey S. Korotin \\ Saratov State Medical University n.a. V.I. Razumovsky, Saratov, Russia
}

Received 30 November 2015, Accepted 25 December 2015

C 2015, Popova Y.V., Korotin A.S.

C 2015, Russian Open Medical Journal

Abstract: The authors presented a letter on the article by Hao et al. published in the September 2015 issue of Circulation Journal.

Keywords: predictors, percutaneous coronary intervention, acute myocardial infarction

Cite as Popova YV, Korotin AS. Clinical predictors of refuse from percutaneous coronary intervention in patients with acute myocardial infarction: which factors are really matters? Russian Open Medical Journal 2016; 5: e0106.

Correspondence to Yulia V. Popova. Address: Research Institute of Cardiology, 141, Cherhishevsky str., Saratov, 410028, Russia. E-mail: doctorup@ mail.ru

We thank Hao et al. for their article published in the September 2015 issue of Circulation Journal [1]. The authors presented some results of MIYAGI-AMI Registry Study (Japan). Clinical characteristics of patients with acute myocardial infarction (AMI) hospitalized between 2002 and 2010 who received primary percutaneous coronary intervention $(\mathrm{PCl})$ and who refused from $\mathrm{PCl}$ were compared. Factors associated with refuse from primary $\mathrm{PCl}$ were separated. Besides huge practical importance the study by $\mathrm{Hao}$ et al. had methodological dignities. They are dividing prehospital phase (time from symptom onset to admission) into 4 time frames $(\leq 2,2-6,6-24$, and $\geq 24 \mathrm{~h})$ and separate analysis of $\mathrm{PCl}$ performance in five age subgroups of AMI patients $(\leq 59,60-69$, $70-79,80-89$, and $\geq 90$ years). These features of the study allow comprehensive analysis of medical care process among AMI patients in the MIYAGI-AMI Registry Study.

But to our opinion the presented study had several limitations.

Firstly, Hao et al. used a restricted set of clinical parameters of AMI patients to reveal predictors of refuse from primary $\mathrm{PCl}$ with the help of multivariate logistic regression analysis (age, sex, history of hypertension, diabetes mellitus, dyslipidemia, current smoking, prior myocardial infarction, infarction site, onset at night, ambulance use for admission, elapsed time from symptom onset to admission, and coexisting acute heart failure on admission). Other authors used expanded set of clinical parameters for similar goal that allow detailed analysis of the clinical status of patients with performed $\mathrm{PCl}$ and patients refused from intervention $[2,3]$. Furthermore, there is no clear description of the criteria for inclusion and exclusion of patients from the study by Hao et al. [1]. In this context, we would deeply appreciate if the authors could share some useful data with us. 1) Please, clarify a basis of selection of clinical characteristics for multivariate analysis? 2) What inclusion and exclusion criteria were used in the presented study?
Secondly, the absence of separation of patients with STsegment elevation myocardial infarction (STEMI) and non-STEMI patients complicates the interpretation of the study results. It is major limitation of the MIYAGI-AMI Registry Study. It is known that ST-segment elevation on electrocardiogram (ECG) is a main factor associated with $\mathrm{PCl}$ performance among patients with acute coronary syndrome [3]. However, in both studies (ref.1 and ref.3) there are some similar results (in particular, the impact of gender and age to $\mathrm{PCl}$ perfomance). The other results of these studies complement each other and, of course, are of great scientific and practical interest.

Conflict of interest: none declared.

Editorial Comments

Editorial have not yet received a response from $\mathrm{K}$. Hao et al. to this letter.

References

1. Hao K, Takahashi J, Ito K, Miyata S, Nihei T, Nishimiya K, et al. Clinical characteristics of patients with acute myocardial infarction who did not undergo primary percutaneous coronary intervention. Circ $J$ 2015; 79: 2009-2016. (doi: 10.1253/circj.CJ-15-0440)

2. Sabouret $P$, Asseman $P$, Dallongeville J, Dujardin JJ, Philippe F, Herrmann MA, et al. Observational study of adherence to European clinical practice guidelines for the management of acute coronary syndrome in revascularized versus non-revascularized patients - the CONNECT Study. Arch Cardiovasc Dis 2010; 103: 437-446. (doi: 10.1016/j.acvd.2010.07.001)

3. Kiselev AR, Popova YV, Posnenkova OM, Gridnev VI, Dovgalevsky PY, Russian Registry of Acute Coronary Syndrome Investigators. Implementation of percutaneous coronary interventions in patients with acute coronary syndrome in Russia and clinical factors influencing on decision making. Cor et Vasa 2014; 56: e1-e10. (doi: 10.1016/j.crvasa.2013.10.005) 
Authors:

Yulia V. Popova - MD, PhD, Researcher, Department of New Cardiological Informational Technologies, Research Institute of Cardiology, Saratov State Medical University n.a. V.I. Razumovsky, Saratov, Russia.

Alexey S. Korotin - MD, PhD Student, Department of New Cardiological Informational Technologies, Research Institute of Cardiology, Saratov State Medical University n.a. V.I. Razumovsky, Saratov, Russia. 